\title{
EDITORIAL
}

\section{Many a slip?}

\author{
A. Bush*,\# and C. Hogg"
}

C ystic fibrosis (CF) is a common disease (up to 1 in 2,000 in some populations), and there is a simple, cheap and reliable diagnostic test which is within the compass of a hospital of any size. Yet even so, wrong diagnoses are not uncommon, because there is a long list of causes of a falsepositive elevation in sweat electrolytes [1]. The most important problem is lack of experience and attention to detail by the operator. Furthermore, borderline cases may need sophisticated testing to establish the diagnosis, such as nasal potential differences or complete sequencing of the CF gene. The consequences of a wrong diagnosis of $\mathrm{CF}$ are potentially serious, including the prescription of inappropriate medications, and the generation of a great deal of anxiety.

The situation with primary ciliary dyskinesia (PCD) is even more complex. The prevalence is debated, and although probably less than CF, PCD is still an important diagnosis to make. Diagnosis is delayed to a greater extent than CF [2], in part because many of the symptoms (cough and a runny nose) are common in normal children [3]. The diagnosis is important; treatment leads to stabilisation of lung function, and those diagnosed late have worse spirometry [4, 5]. Furthermore, PCD upper airway disease, specifically chronic secretory otitis media, has different implications than the same problem in otherwise normal children [6, 7]. However, the diagnostic difficulties, particularly in terms of false positives, are much greater in PCD than in CF.

The diagnostic pathway for PCD will often start with the elimination of commoner causes of respiratory symptoms, for example CF and hypogammaglobulinaemia, unless there are clear pointers to the diagnosis, such as unexplained neonatal respiratory distress in a baby with mirror image arrangement [8]. A number of screening tests for PCD have been advocated. Ciliary function can be measured in vivo using the saccharine test [9], or radionuclide isotope scanning [10], and if normal, may obviate the need for further testing. However, if the patient sniffs during the saccharine test, a taste may be reported, and PCD eliminated incorrectly. Nasal nitric oxide (nNO) is almost invariably low in PCD [11], but this is not specific, and low $\mathrm{nNO}$ has been reported in CF [12] and diffuse panbronchiolitis [13]. Hence, these screening tests can never be used to make a positive diagnosis of PCD; definitive diagnostic testing is mandatory.

\footnotetext{
*Paediatric Respirology, Imperial School of Medicine at National Heart and Lung Institute ${ }^{*}$ Honorary Consultant Paediatric Chest Physician, Royal Brompton Hospital, "Consultant Paediatrician, Royal Brompton Hospital, London, UK.

CORRESPONDENCE: A. Bush, Dept of Paediatric Respiratory Medicine, Royal Brompton Hospital Sydney Street, London SW3 6NP, UK. E-mail: a.bush@rbh.nthames.nhs.uk
}

Although newer diagnostic tests such as gene analysis [14] and staining of specific dynein proteins [15] are being developed, the mainstay of diagnosis of PCD remains the careful and detailed assessment of ciliary function and structure, usually on fresh but sometimes on cultured cells [8]. These are not simple tests, and should only be performed in tertiary centres that have built up expertise over a period of years. Ciliated epithelium is usually obtained by nasal brush biopsy. Ciliary beat frequency $(\mathrm{CBF})$ and pattern is recorded from frame by frame analysis using a high speed video-camera. In some cases, the beat pattern may be strongly suggestive of particular pathological abnormalities [16]. Meticulous attention to detail is essential, and this is underscored by a manuscript in the current issue of the European Respiratory Journal [17]. The group, which has been at the forefront of diagnostic studies in PCD for many years, now report for the first time that $\mathrm{CBF}$ varies depending on whether it is measured on single cells or on epithelial strips. If single cells are used, then potentially misleading results may be obtained. This is important, because some genuine cases of PCD have normal ciliary ultrastructure and diagnosis rests on $\mathrm{CBF}$ and the clinical picture.

Completing the diagnostic pathway is electron microscopy, which should involve a careful examination of a large number of cilia by an experienced and enthusiastic electron microscopist. Image enhancement using computer algorhythms may assist the process [18]. It is essential to avoid confusing ultrastructural changes secondary to viral infection, with those of PCD. Increasingly, epithelial cell culture is used in difficult cases [19]; if the structural and functional changes seen in the fresh cells are secondary, they will disappear after culture.

The study by THOMAs et al. [17] is very timely, because diagnostic testing for PCD is a particularly hot topic in Europe. The European Respiratory Society (ERS) Task Force has produced the largest ever survey of cases of PCD, parts of which were presented at the recent congress as posters [20,21] and a hot topic. It is very clear that in many parts of Europe, there is no access to the correct diagnostic pathways [8], and even in those countries where the diagnostic tests exist, many patients are not being referred for proper testing. Thus, there is a real chance that some children labelled as having PCD may in fact just be otherwise normal, catarrhal children. This is an important failing which needs to be addressed, for several reasons. First, although the management of PCD lower airway disease is not dissimilar to that of idiopathic bronchiectasis, the management of the otological issues in PCD, specifically chronic secretory otitis media, is quite different from that in otherwise healthy children [6,7], and failure to make the diagnosis of PCD can lead to unnecessary and unacceptable morbidity. Specifically, surgical procedures, in particular 
tympanostomy tube insertion, are avoided because they lead to prolonged, offensive otorrhea and do not improve hearing. Secondly, there is a clear need to undertake proper therapeutic trials in clearly defined groups of PCD patients, to improve the current, virtually nonexistent evidence base for treatment. If the trial is diluted with non-PCD patients, or nonspecifically chesty children, then wrong conclusions may be drawn. Not all bronchiectatic patients respond equally well to a given treatment; the disappointing effects of rhDNAse in idiopathic bronchiectasis [22] are in marked contrast to CF [23]. Finally, a new era of therapy for genetic diseases is being opened up; for example, PTC124 (ataluren), which over-rides premature stop codons, may potentially be helpful in up to $30 \%$ of genetic diseases [24]. Some evidence of benefit has already been shown in CF [25]. However, before the victim of a genetic disease can benefit from therapy, the disease has first got to be accurately diagnosed, and currently large numbers of Europeans do not have access to state of the art diagnostic procedures.

The problem having been highlighted by the ERS Task Force, what are the solutions? The European Union has devoted much praiseworthy effort to the elimination of inequalities across Europe. It is clear that the expense and sophistication of a diagnostic laboratory for PCD is such that relatively few centres across Europe will be able to offer testing. In the UK, it took central government funding to put PCD diagnostic testing on a sound financial basis; is this a model that the EU should adopt, offering funding to appropriate centres in relatively resource poor areas to diagnose PCD? There should be strings attached, as in the UK; centres would need to keep a database, collaborate with the other centres in the network, and undergo regular audits of the diagnostic procedures. But it would mean that across Europe, we could collect together a sufficiently large number of well characterised PCD patients to start to fill the evidence gaps in the treatment of this condition.

\section{STATEMENT OF INTEREST}

None declared.

\section{REFERENCES}

1 Wallis C. Diagnosing cystic fibrosis: blood, sweat, and tears. Arch Dis Child 1997; 76: 85-88.

2 Coren ME, Meeks M, Buchdahl RM, et al. Primary ciliary dyskinesia (PCD) in children - age at diagnosis and symptom history. Acta Paediatrica 2002; 91: 667-669.

3 Bush A, O'Callaghan C. Primary ciliary dyskinesia. Arch Dis Child 2002; 87: 363-365.

4 Ellerman A, Bisgaard H. Longitudinal study of lung function in a cohort of primary ciliary dyskinesia. Eur Respir J 1997; 10: 23762379.

5 Noone PG, Leigh MW, Sannuti A, et al. Primary ciliary dyskinesia: diagnostic and phenotypic features. Am J Respir Crit Care Med 2004; 169: 459-467.
6 Hadfield PJ, Rowe-Jones JM, Bush A, et al. Treatment of otitis media with effusion in children with primary ciliary dyskinesia. Clin Otolaryngol 1997; 22: 302-306.

7 Majitha A, Fong J, Hariri M, et al. Hearing outcomes in children with primary ciliary dyskinesia - a longitudinal study. Int J Ped Otorhinolaryngol 2005; 69: 1061-1064.

8 Bush A, Chodhari R, Collins N, et al. Primary ciliary dyskinesia. Arch Dis Child 2007; 92: 1136-1140.

9 Canciani M, Barlocco EG, Mastella G, et al. The saccharin method for testing mucociliary function in patients suspected of having primary ciliary dyskinesia. Pediatr Pulmonol 1988; 5: 210-214.

10 Marthin JK, Mortensen J, Pressler T, et al. Pulmonary radioaerosol mucociliary clearance in diagnosis of primary ciliary dyskinesia. Chest 2007; 132: 966-976.

11 Karadag B, James AJ, Gultekin E, et al. Nasal and lower airway level of nitric oxide in children with primary ciliary dyskinesia. Eur Respir J 1999; 13: 1402-1406.

12 Balfour-Lynn IM, Laverty A, Dinwiddie R. Reduced upper airway nitric oxide in cystic fibrosis. Arch Dis Child 1996; 75: 319-322.

13 Nakano $\mathrm{H}$, Ide $\mathrm{H}$, Imada $\mathrm{M}$, et al. Reduced nasal nitric oxide in diffuse panbronchiolitis. Am J Respir Crit Care Med 2000; 162: 22182220

14 Geremek M, Witt M. Primary ciliary dyskinesia: genes, candidate genes and chromosomal regions. J Appl Genet 2004; 45: 347-361.

15 Fliegauf M, Olbrich H, Horvath J, et al. Mislocalization of DNAH5 and DNAH9 in respiratory cells from patients with primary ciliary dyskinesia. Am J Respir Crit Care Med 2005; 171: 1343-1349.

16 Chilvers MA, Rutman A, O'Callaghan C. Ciliary beat pattern is associated with specific ultrastructural defects in primary ciliary dyskinesia. J Allergy Clin Immunol 2003; 112: 518-524.

17 Thomas B, Rutman A, O'Callaghan C. Disrupted ciliated epithelium shows slower ciliary beat frequency and increased dyskinesia. Eur Respir J 2009; 34: 401-404.

18 Escudier E, Couprie M, Duriez B, et al. Computer-assisted analysis helps detect inner dynein arm abnormalities. Am J Respir Crit Care Med 2002; 166: 1257-1262.

19 Jorissen M, Willems T, Van der Schueren B, et al. Ultrastructural expression of primary ciliary dyskinesia after ciliogenesis in culture. Acta Otorhinolaryngol Belg 2000; 54: 343-356.

20 Strippoli MP, Frischer T, Barbato A, et al. ERS Task Force. Age at diagnosis in children with primary ciliary dyskinesia (PCD) across Europe. Eur Respir J 2008; 32: Suppl. 52, 714 S.

21 Maurer E, Barbato A, Frischer T, et al. ERS Task Force. Treatments for primary ciliary dyskinesia (PCD) in children across Europe. Eur Respir J 2008; 32: Suppl. 52, 714S.

22 Wills PJ, Wodehouse T, Corkery K, et al. Short-term recombinant human DNase in bronchiectasis. Effect on clinical state and in vitro sputum transportability. Am J Respir Crit Care Med 1996; 154: 413-417.

23 Fuchs HJ, Borowitz DS, Christiansen DH, et al. Effect of aerosolized recombinant human DNase on exacerbations of respiratory symptoms and on pulmonary function in patients with cystic fibrosis. The Pulmozyme Study Group. N Engl J Med 1994; 331: 637-642.

24 Kerem E, Hirawat S, Armoni S, et al. Effectiveness of PTC124 treatment of cystic fibrosis caused by nonsense mutations: a prospective phase II trial. Lancet 2008; 372: 719-727. 